\title{
USE OF COMPUTERS IN SPECIAL EDUCATION: BENEFITS AND OUTCOMES
}

\author{
Basak Baglama $^{1}$, Yucehan Yucesoy ${ }^{2}$, Mukaddes Sakalli Demirok ${ }^{3, *}$ \\ ${ }^{1}$ Department of Special Education, Atatürk Education Faculty, Near East University, North Cyprus, Mersin 10 \\ Turkey, basak.baglama@neu.edu.tr \\ ${ }^{2}$ Department of Teaching Arts, Atatürk Education Faculty, Near East University, North Cyprus, Mersin 10 \\ Turkey, yucehan.yucesoy@neu.edu.tr \\ ${ }^{3}$ Department of Special Education, Atatürk Education Faculty, Near East University, North Cyprus, Mersin 10 \\ Turkey, mukaddes.sakalli@neu.edu.tr \\ Correspondence: mukaddes.sakalli@ neu.edu.tr ; Tel.: +90 (392) 2236464
}

\begin{abstract}
Use of computers as effective technological tools in special education has become prevalent in the recent years since it enhances teaching concepts and skills and increase permanence and generalization of learned concepts and skills. Identifying the current situation and trends in a specific field provides a comprehensive perspective for researchers and practitioners. This study aims to examine the current situation and trends in the studies on special education and computer through content analysis. Scopus database was examined in the study in order to carry out the content analysis. Articles published in Scopus database were examined based on certain criteria including year of publication, name of the journals, document type, country and subject area. Data were analyzed based on content analysis method. Results are discussed with reference to relevant literature and implications for further research and practices are also provided.
\end{abstract}

Keywords: computer, special education, benefit, content analysis

\section{Introduction}

Today, it is widely known that using technology promotes appropriate facilities for educational practices. In recent years, there is a dramatic increase in the amount of knowledge and this has an important influence in education and technology facilitates easy access to knowledge (Domingo \& Gargante, 2016; Englund, Olofsson \& Price, 2017). Technologies which entered rapidly into the field of education provide solutions for problems in education and enhance capacity and variability. Developments and innovations in technology change the structure of education and therefore structure of education which will make individuals to adapt to the society need to change as well. Modern technologies are considered as the outcomes of differences caused by technological developments and innovations in education. In light of these developments, method and content of education also changes. Accordingly, educational technology involves every kind of system, technic and support which are formed to develop learning and teaching process in every stage of education beginning from early childhood to higher education (Blackwell, Lauricella \& Wartella, 2014; Sezgin, Erdogan \& Erdogan, 2017).

According to Plowman and Stephen (2005), use of technology is regarded as appropriate when it facilitates effective teaching and learning and provides positive developmental outcomes for learners. For instance, interactive reading-writing programs promotes early reading and writing when compared with other traditional methods. Today, teachers prefer 
digital materials rather than printed materials in teaching concepts and skills. The reason for the prevalent use of technology is related with the effective practices. In addition, content of education could be presented with technology in various ways (Wainwright \& Linebarger, 2006). There are main points which should be considered for an effective collaboration between technology and education (Zoch \& Myers, 2017; Saltan, Turkyilmaz, Karacalti \& Bilir, 2018). These main points are as follows:

- Ways of achieving educational goals when there is no technology,

- Whether technology helps teachers to achieve educational goals,

- Use of technology is appropriate for students' ages,

- Use of technology is appropriate for education programs,

- Educational strategies for technology use,

- Integration of technology into education,

- Technology as a mediator for students to take active role in learning process,

- Whether using technology facilitates family involvement.

There are various technological tools used in education. One of the most prevalently used technological tool in education are computers. Accordingly, concept of "computer-supported education" has come to the fore in the recent years. Given the effective use of technological tools in education including technology, these tools are both used in regular and special education settings and environments (Yadav, Gretter, Hambrusch \& Sands, 2016; McKissick, Diegelmann \& Parker, 2017). Many different methods are used in the education of individuals with special needs and use of technology has become prevalent in special education as well. Use of computers and other technological tools are arranged based on the different needs of individuals with special needs. Contributions of using computers in special education and interests and attitudes of students towards computers and other technologies need to be determined. Computers are considered as a kind of teacher / teaching tool in the lives of individuals with special needs (Johnson, 2013).

In addition to the mentioned advantages of using computers in special education, it should be also noted that using computers promotes permanence and generalization. However, in order to achieve this; student characteristics, content and environment need to be purely determined and organized based on the needs of individuals with special needs. According to the literature, there are certain aims of using technology that enhances special education and rehabilitation practices (Adebisi, Liman \& Longpoe, 2015). These aims generally focus on the following objectives:

- Individuals with special needs should gain communication skills and solutions for social environment and communication problems should be found.

- Individuals with special needs should maintain their lives independently in the society and learn basic life skills.

- Individuals with special needs could be able to use their existing body and mind capacities at the maximum level.

- Individuals with special needs should gain occupational skills if appropriate.

When the literature on special education and use of computers is examined, it is seen that use of computer in special education as a field develops rapidly and there are large amount of researches showing the effectiveness of using computers in special education among individuals with intellectual disability, down syndrome, autism spectrum disorder, learning disability and other special education categories (Stultz, 2013; Lorah, Parnell, Whitby \& Hantula, 2015; Dogan \& Akdemir, 2015; Vereenooghe, Gega, Reynolds \& Langdon, 2016; 
Felix, Mena, Ostos \& Maestre, 2017). In this context, large amount research in this field indicates that there are important developments in the field. Therefore, identifying the current situation and trends in the studies related with computers and special education would enlighten the further research and practices. Therefore, this study aims to examine the studies related with computer and special education in Scopus and reveal the current situation and trends.

\section{Method}

\subsection{Research Model}

Content analysis as a qualitative method was used in this study to examine the published documents related with computer and special education in Scopus database which is one of the international academic databases that indexes a wide variety of journal sources. Content analysis is defined as the examination of verbal or written materials objectively and systematically (Karasar, 2005; Stemler, 2015).

\subsection{Data Collection}

Scopus was selected as the database for the study. The published documents were obtained through searching keywords "computer" and "special education" in order to reveal the current situation and trends in this field. The search page appeared after entering these keywords is provided in Figure 1. All documents published in Scopus on this topic were included in the study and a total number of 4523 published documents were searched, identified and obtained based on the search for the study.

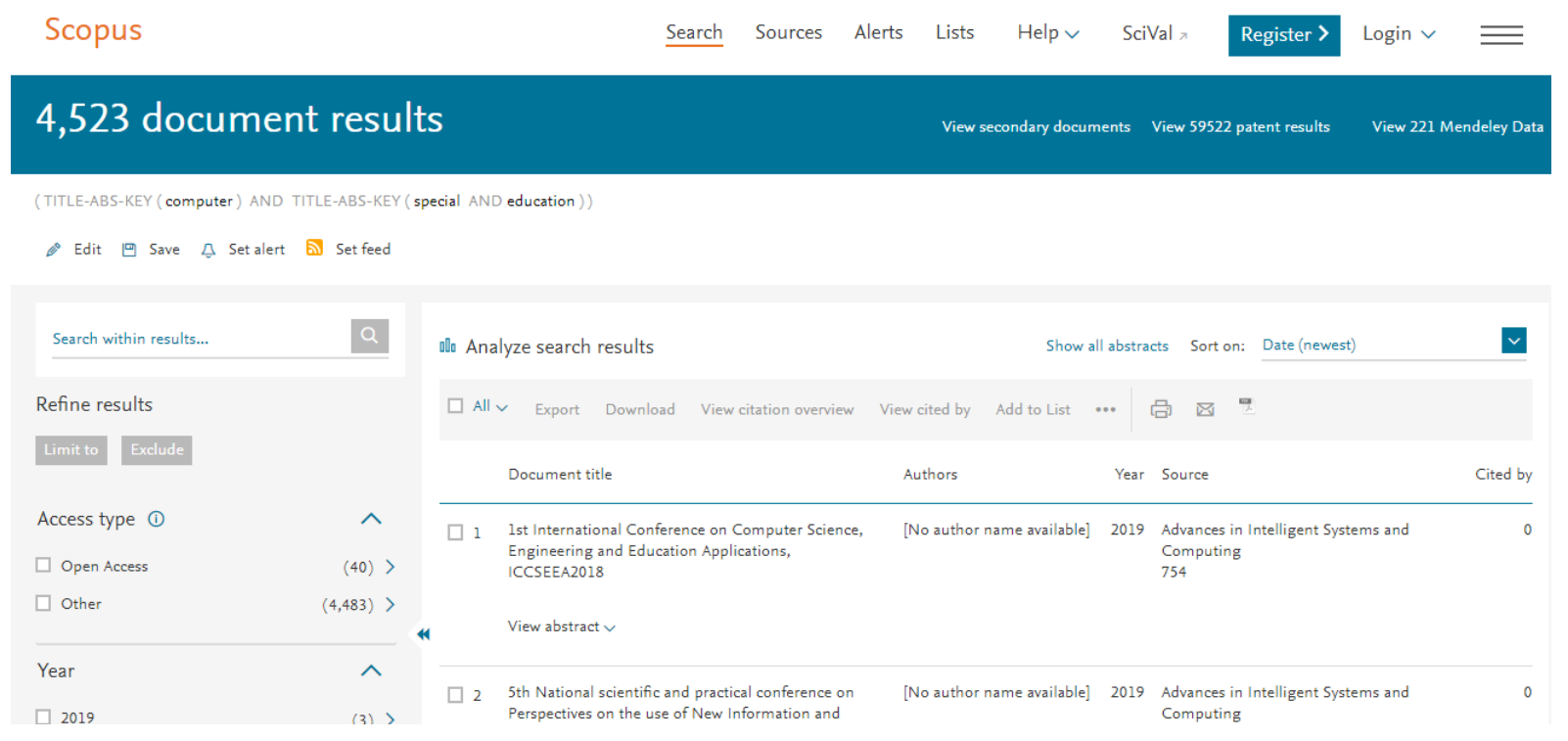

Figure 1. SCOPUS search page for "computer" and "special education"

\subsection{Data Analysis}

Content analysis criteria were determined to examine the published documents in Scopus database for data analysis. These criteria included year of publication, name of the journals, document type, country and subject area. Data were provided with frequency and percentages in tables and figures. 


\section{Results}

\subsection{Distribution of the Published Documents Based On the Year of Publication}

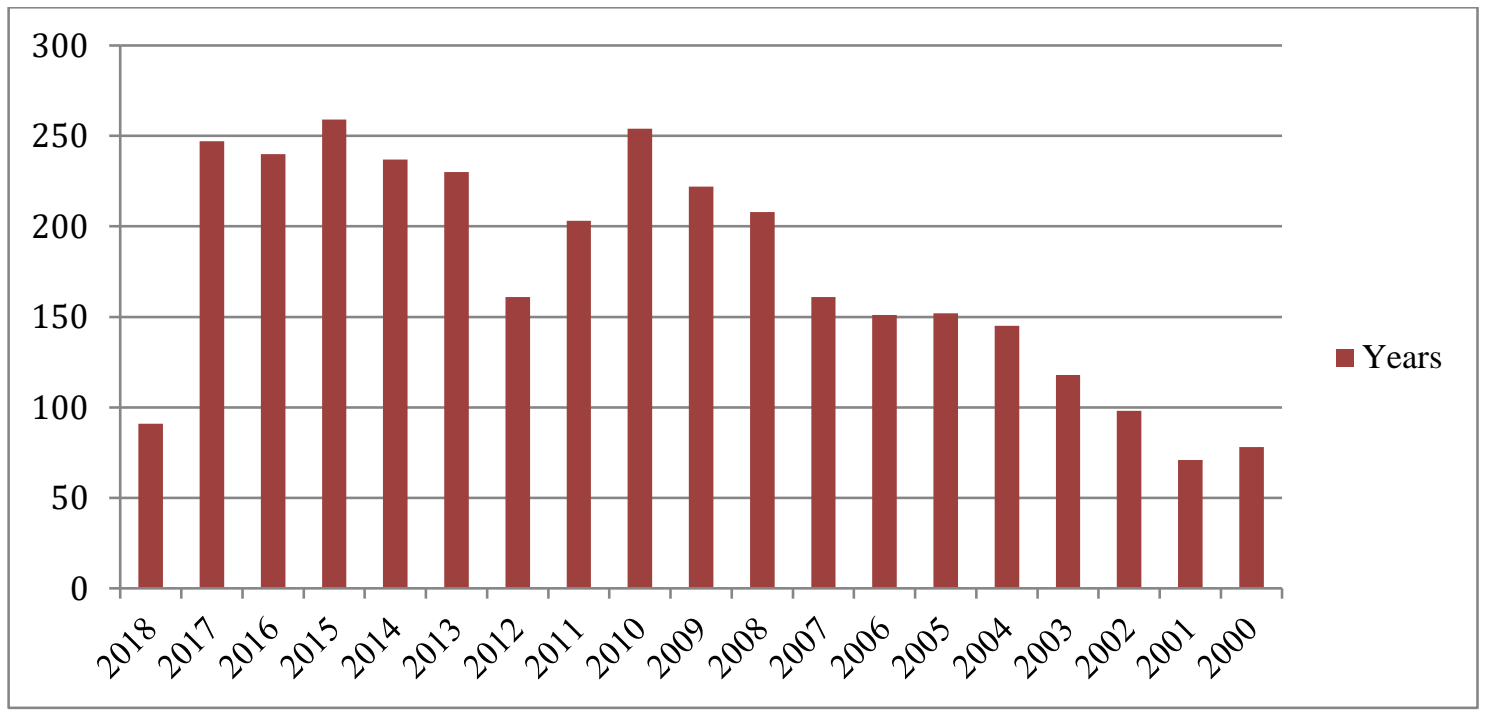

Figure 2. Distribution of the Published Documents Based On the Year of Publication

Figure 2 shows the distribution of the published documents related with computers and special education based on the year of publication in SCOPUS database. The years beginning from 2000 are included in the figure. Results showed that the highest number of publication was in 2015 and 2009. As it can be seen, there is a steady increase in the number of publications on computers and special education throughout the years. The reason of lower number of publication in 2018 is that publications until the end of May 2018 are considered as the data for the study.

\subsection{Distribution of the Published Documents Based On the Name of the Journals}

Table 1. Name of the Journals in Which the Documents Published

\section{Name of journal}

Lecture Notes in Computer Science

American Annals of the Deaf

Communications in Computer and Information Science

Proceedings Frontiers In Education Conference

Journal of Learning Disabilities

Computers and Education

Studies in Health Technology and Informatics

IFIP Advances in Information and Communication Technology

Advances in Intelligent Systems and Computing f $\quad \%$

\begin{tabular}{ll}
221 & 4.89 \\
121 & 2.68 \\
63 & 1.39 \\
55 & 1.21 \\
54 & 1.19 \\
43 & 0.95 \\
38 & 0.85 \\
36 & 0.79 \\
35 & 0.77 \\
32 & 0.71 \\
\hline
\end{tabular}

Table 1 shows the name of the journals in which the documents related with computers and special education were published. The first 10 journals with frequent publications are included in the table. According to the results, it is seen that the highest number of publication is in Lecture Notes in Computer Science $(\mathrm{f}=221,4.89 \%)$. This result is followed by American 
Annals of the Deaf $(\mathrm{f}=121,2.68 \%)$ and Communications in Computer and Information Science ( $f=63,1.39 \%$ ). Results showed that there are many different journals which published articles on computers and special education. When the names of the journals are considered, it is also seen that there are different scopes of journals including education, computer science, health technology, informatics, information and communication technology, learning disability and hearing impairment.

\subsection{Distribution of the Published Documents Based On Document Type}

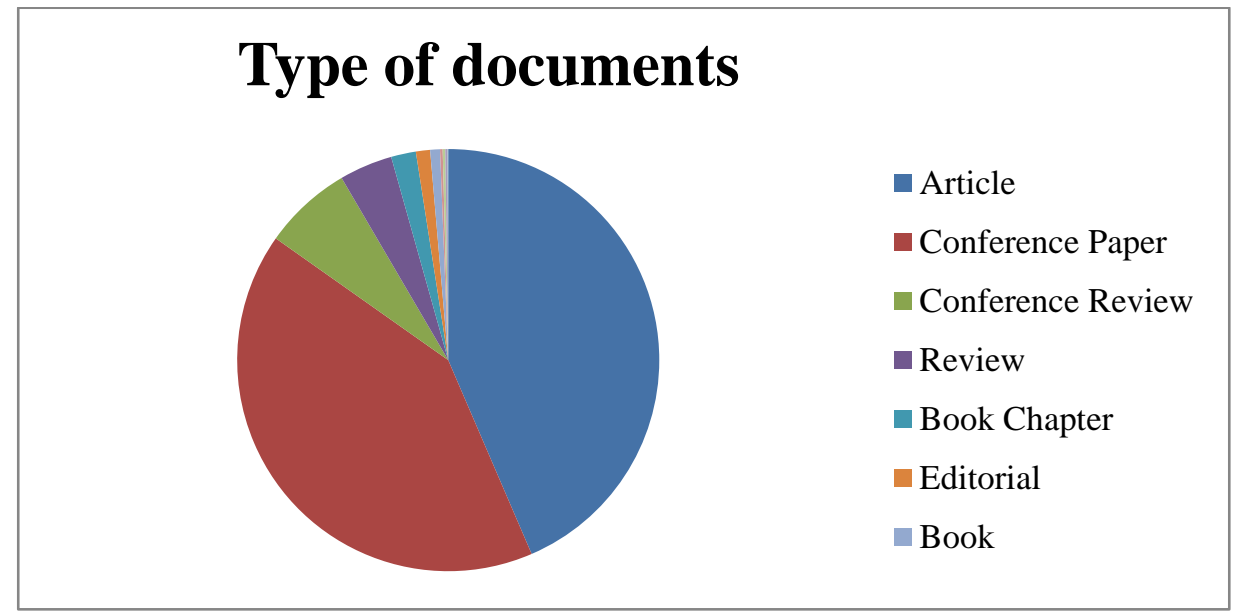

Figure 3. Distribution of the Published Documents Based On Document Type

Distribution of the published documents based on the type of document is provided in Figure 3. As it can be seen from the figure, majority of the published documents were articles and conference papers. Therefore, it can be inferred that authors prefer publishing research articles and conference papers rather than other types of documents. Other types of documents included conference review, book review, review, book chapter, editorial and books.

\subsection{Distribution of the Published Documents Based On the Subject Area}

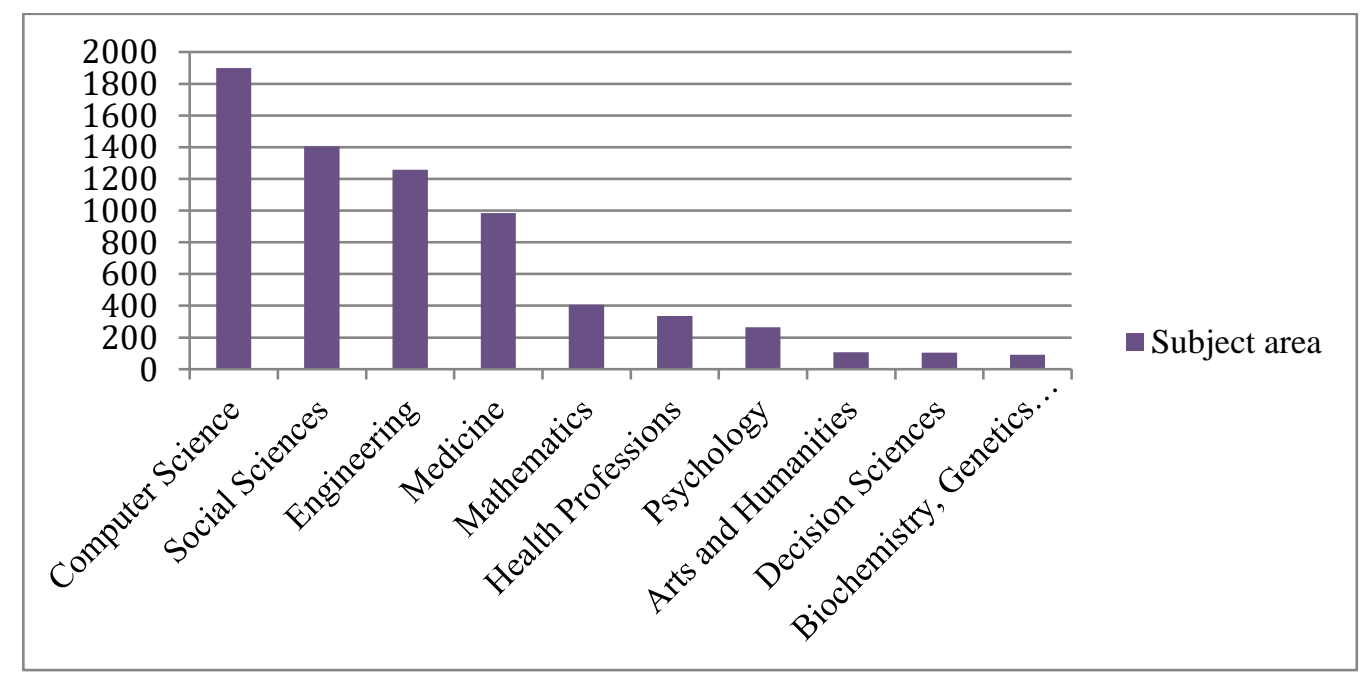

Figure 4. Distribution of the Published Documents Based On Subject Area

Figure 4 shows the distribution of the published documents based on the subject area. The first 10 frequently studied subject area are involved in the figure. Other subject areas were not included in the figure since they have lower frequencies. As it can be seen, computer science was the most frequently studied subject area in the published documents related with computers 
and special education. In addition, social sciences, engineering, medicine, mathematics, health professions, psychology, arts and humanities, decision sciences and genetics were the other frequently studied subject areas from the computer and special education fields. Therefore, it could be inferred that there are various different research topics which studied in the published documents regarding computers and special education.

\subsection{Distribution of the Published Documents Based On Country}

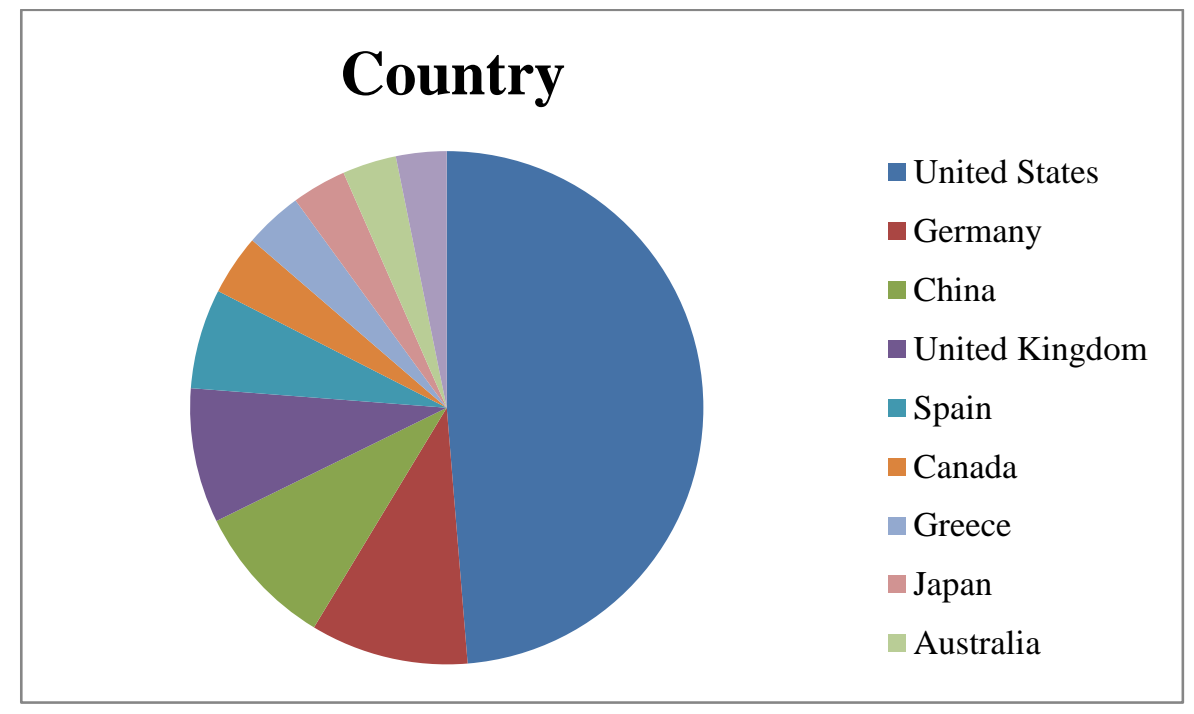

Figure 5. Distribution of the Published Documents Based On Country

Figure 5 demonstrates the distribution of the published documents based on country. The first 10 countries were included in the figure because the other countries were with lower frequencies. According to the results, it is seen that United States is the first country with highest number of publications related with computers and special education in Scopus database. In addition, Germany, China, United Kingdom and Spain were the other countries with high number of publications on computers and special education. These results were followed with Canada, Greece, Japan, Australia and Netherlands.

\section{Discussion}

Computer as a technological tool provides many opportunities for individuals with special needs in terms of many dimensions in order to improve life standards in the society, participate into social life and maintain various skills for learning a profession or living independently in the society. Computers are really important in the education of individuals with special needs. Computer-supported education programs are frequently used in teaching many academic skills such as mathematics, reading-writing, communication skills, other life skills including selfcare skills and daily living skills and basic concepts such as shape, color and opposite concepts. In addition to teaching these skills, computers help individuals with special needs to learn and transfer new knowledge and skills to other situations (Ok, 2018). Given these positive outcomes of computers for individuals with special needs, this study aimed to examine the current situation and trends in the studies on special education and computer through content analysis in order to constitute a systematic review of the scientific research. A total number of 4523 published articles were examined based on previously determined content analysis criteria. 
According to the results obtained from this study, there is a steady increase in the number of publications on computers and special education throughout the years. This is primarily related with the increase in the understanding of effectiveness of computers for individuals with special needs in terms of various dimensions. For instance, Wainer and Ingersoll (2011) emphasized that computers are important tools for teaching social communication to individuals with autism spectrum disorders. Results also showed that there are many different journals which published articles on computers and special education. This might be related with multi-disciplinary nature of the fields of special education and computer research.

Furthermore, results revealed that authors prefer publishing research articles and conference papers rather than other types of documents. As it can be seen, computer science was the most frequently studied subject area in the published documents related with computers and special education. In addition, social sciences, engineering, medicine, mathematics, health professions, psychology, arts and humanities, decision sciences and genetics were the other frequently studied subject areas from the computer and special education fields. Therefore, it could be inferred that there are various different research topics which studied in the published documents regarding computers and special education. Lastly, results showed that United States is the first country with highest number of publications related with computers and special education in Scopus database. Similar with this result, Demirok, Baglama and Besgul (2015) carried out a content analysis study on special education and found that most articles have been published by the authors from United States.

\section{Conclusion and Recommendations}

In this study, current situation and recent research trends in the published studies on computers and special education in Scopus database were determined. In the light of the results obtained from the study, the following recommendations are provided for further research and practices:

- Different databases might be examined for content analysis in order to reveal the current situation and trends in special education and computer research from a more comprehensive perspective.

- Similar studies should be repeated periodically in the future to compare past and current trends.

- In this study, special education as a general category has been investigated. Future studies might examine specific diagnosis and effectiveness of computer applications.

- Special education professionals might receive more training about how to integrate computers into special education practices and be more competent.

\section{References}

Adebisi, R. O., Liman, N. A., \& Longpoe, P. K. (2015). Using assistive technology in teaching children with learning disabilities in the 21st century. Journal of Education and Practice, 6(24), 14-20

Demirok, M. S., Baglama, B., \& Besgul, M. (2015). A content analysis of the studies in special education area. Procedia: Social and Behavioral Sciences, 197, 2459-2467

Dogan, I., \& Akdemir, O. (2015). Ozel egitimde bilgisayar destekli ogretim: uc durum calismasi. Journal of Higher Education \& Science, 5(2), 165-177 
Domingo, M. G., \& Gargante, A. B. (2016). Exploring the use of educational technology in primary education: Teachers' perception of mobile technology learning impacts and applications' use in the classroom. Computers in Human Behavior, 56, 21-28

Englund, C., Olofsson, A. D., \& Price, L. (2017). Teaching with technology in higher education: understanding conceptual change and development in practice. Higher Education Research \& Development, 36(1), 73-87

Felix, V. G., Mena, L. J., Ostos, R., \& Maestre, G. E. (2017). A pilot study of the use of emerging computer technologies to improve the effectiveness of reading and writing therapies in children with Down syndrome. British Journal of Educational Technology, $48(2), 611-624$

Johnson, G. M. (2013). Using tablet computers with elementary school students with special needs: The practices and perceptions of special education teachers and teacher assistants. Canadian Journal of Learning and Technology, 39(4), 1-12

Karasar, N. (2005). Bilimsel arastirma yontemleri. Ankara: Nobel Yayin Dagitim

Lorah, E. R., Parnell, A., Whitby, P. S. \& Hantula, D. (2015). A systematic review of tablet computers and portable media players as speech generating devices for individuals with autism spectrum disorder. Journal of Autism and Developmental Disorders, 45(12), 3792-3804

McKissick, B. R., Diegelmann, K. M., \& Parker, S. (2017). Using technology to address barriers in rural special education for students with autism: A do-it-yourself guide. Rural Special Education Quarterly, 36(3), 155-159

Ok, M. W. (2018). Use of ipads as assistive technology for students with disabilities. TechTrends, 62(1), 95-102

Plowman, L., \& Stephen, C. (2005). Children, play, and computers in pre-school education. British Journal of Educational Technology, 36(2), 145-157

Saltan, F., Turkyilmaz, T., Karacalti, C., \& Bilir, K. (2018). Use of current educational technology in science education: A scoping review. Cukurova University Faculty of Education Journal, 47(1), 308-336

Sezgin, F., Erdogan, O., \& Erdogan, B. H. (2017). Ogretmenlerin teknoloji oz yeterlikleri: Ogretmen ve ogrenci goruslerine yonelik butuncul bir analiz. Egitim Teknolojisi Kuram ve Uygulama, 7(1), 180-199

Stemler, S. E. (2015). Content analysis. Emerging Trends in the Social and Behavioral Sciences: An Interdisciplinary, Searchable, and Linkable Resource, 1, 1-14

Stultz, L. S. (2013). The Effectiveness of computer-assisted instruction for teaching mathematics to students with specific learning disability. Journal of Special Education Apprenticeship, 2(2), 1-13

Vereenooghe, L., Gega, L., Reynolds, S., \& Langdon, P. E. (2016). Using computers to teach people with intellectual disabilities to perform some of the tasks used within cognitive behavioural therapy: A randomised experiment. Behaviour Research and Therapy, 76, $13-23$

Wainer, A. L., \& Ingersoll, B. R. (2011). The use of innovative computer technology for teaching social communication to individuals with autism spectrum disorders. Research in Autism Spectrum Disorders, 5(1), 96-107 
Wainwright, D. K., \& Linebarger, D. L. (2006). Ready to learn: Literature review. UK: Children's Media Center

Yadav, A., Gretter, S., Hambrusch, S., \& Sands, P. (2016). Expanding computer science education in schools: understanding teacher experiences and challenges. Computer Science Education, 26(4), 235-254

Zoch, M., \& Myers, J. (2017). Teachers' engagement with new literacies as support for implementing technology in the english/language arts classroom. Contemporary Issues in Technology and Teacher Education, 17(1), 25-52

\section{Biodata of the Corresponding Author}

Sakalli Demirok, Mukaddes, Associate Professor, Near East University, and head of the department of special education. She is an author, researcher and lecturer whose interest include special education, giftedness, hearing impairments, down syndrome, autism and scientific study of education. 